NBER WORKING PAPER SERIES

\title{
AN INTEGRATED MODEL OF DOWNTOWN PARKING AND TRAFFIC CONGESTION
}

\author{
Richard Arnott \\ Eren Inci \\ Working Paper 11118 \\ http://www.nber.org/papers/w11118
}

\author{
NATIONAL BUREAU OF ECONOMIC RESEARCH \\ 1050 Massachusetts Avenue \\ Cambridge, MA 02138 \\ February 2005
}

This paper draws on Ch. 2 of Alleviating Urban Traffic Congestion (Arnott, Rave, and Schoeb, forthcoming), entitled "Some Downtown Parking Arithmetic". Authors would like to thank seminar participants at CESifo, Boston College, West Virginia University, University of Lugano, and the University of Calgary, session participants at the 2005 ASSA Meetings, especially the discussant Stef Proost, as well as Ronnie Schoeb, for helpful comments. The views expressed herein are those of the author(s) and do not necessarily reflect the views of the National Bureau of Economic Research.

(C) 2005 by Richard Arnott and Eren Inci. All rights reserved. Short sections of text, not to exceed two paragraphs, may be quoted without explicit permission provided that full credit, including $\odot$ notice, is given to the source. 
An Integrated Model of Downtown Parking and Traffic Congestion

Richard Arnott and Eren Inci

NBER Working Paper No. 11118

February 2005

JEL No. R4

\section{ABSTRACT}

This paper presents a downtown parking model that integrates traffic congestion and saturated onstreet parking. We assume that the stock of cars cruising for parking adds to traffic congestion. Two major results come out from the model, one of which is robust. The robust one is that, whether or not the amount of on-street parking is optimal, it is efficient to raise the on-street parking fee to the point where cruising for parking is eliminated without parking becoming unsaturated. The other is that, if the parking fee is fixed at a sub-optimal level, it is second-best optimal to increase the amount of curbside allocated to parking until cruising for parking is eliminated without parking becoming unsaturated.

Richard Arnott

Department of Economics

Boston College

Chestnut Hill, MA 02467-3806

and NBER

arnottr@bc.edu

Eren Inci

Department of Economics

Boston College

Chestnut Hill, MA 02467-3806

inci@bc.edu 


\section{Introduction}

Some newspaper articles have asserted that during business hours half the cars on downtown streets in large cities are cruising for parking. If the claim is true, substantially reducing cruising for parking in downtown areas could result in huge travel savings. In fact, traffic experts simply do not know what proportion of cars on downtown city streets are cruising for parking. Shoup (2005) presents a table summarizing the results of thirteen studies on cruising for parking. Across the studies, the average share of traffic cruising for parking was $30 \%$ and the average cruising time 7.8 minutes. While the methods employed and the generality of the results are open to question ${ }^{1}$, it is fair to say that current expert opinion is that cruising for parking adds substantially to the severity of downtown traffic congestion. It is therefore remarkable that the phenomenon has not been more widely studied by urban transportation researchers.

This paper is the first to look at cruising for parking from an economic perspective. It provides a thorough analysis of just about the simplest possible model that can be employed to analyze the phenomenon. The central features of the model are that the demand for downtown parking is sensitive to both the money and time costs of a downtown trip, parking is available only on-street and may be saturated (as soon as a parking space is vacated, it is taken by a car that is cruising for parking), and travel speed depends on the density of cars cruising for parking and the amount of on-street parking, as well as the density of cars in transit. It is assumed that the level of demand is sufficiently high that providing parking free results in saturated parking and cruising for parking. Cruising for parking raises the full price of a downtown trip, and the level of cruising for parking adjusts to clear "the market" for parking. The principal simplifying assumptions are that downtown is spatially homogeneous, downtown traffic is in a steady state, drivers are identical, and all travel is by car. Subsequent papers will enrich the model to allow for driver heterogeneity, mass transit, and off-street parking, which will permit significantly richer policy analysis. The primary goal of this paper is to lay the groundwork by developing terminology, concepts, and an analytical framework.

Despite its simplicity, the model generates some interesting results. The first is that cruising for parking is pure deadweight loss. Consider an initial situation in which on-street parking is provided free and cruising for parking occurs. The equilibrium full price of a trip is determined by parking availability relative to the level of demand. Imposing a parking fee

\footnotetext{
${ }^{1}$ Almost all were one-off studies of cruising for parking in a localized area of a major city. The areas were probably chosen because cruising for parking was perceived to be a problem there. Furthermore, the methods employed have varied across studies. In most studies, randomly-selected cars are followed by car or bicycle, though in a couple of recent studies the information is extracted from aerial video photography.
} 
at a level such that parking remains saturated does not alter the equilibrium full price of a trip and therefore has no effect on consumer surplus, but generates parking fee revenue. Thus, the parking fee raises revenue with no burden at all. The second is that the parking fee should be raised to the point where cruising for parking is eliminated but parking remains saturated. The third is that, when the level of the parking fee is fixed, the amount of curbside allocated to parking should be increased to the point where cruising for parking is eliminated but parking remains saturated.

The paper is organized as follows. Section 2 provides a brief review of the literature on the economics of parking. Section 3 presents the model. Section 4 analyzes the model in detail, and section 5 calibrates it to investigate the effects of the limited range of policies the model permits. Section 6 discusses some possible extensions, while still retaining the assumptions that all travel is by car and all parking is on street. Section 7 concludes the paper.

\section{Literature Review}

The literature on the economics of parking is small. Until a decade ago, the economics literature looked at parking almost exclusively (but see Douglas (1975)) as a fixed fee added on at the end of an auto trip. By increasing the full price of an auto trip, parking fees affect travel demand and modal choice. One early example is Gillen and Westin (1978) that incorporated parking charges into an empirical model of modal choice in Toronto. Calthrop, Proost, and van Dender (2000) is a more recent study that examined the second-best level of the parking fee when congestion tolls cannot be imposed on city streets.

Some other papers have looked at other aspects of parking and parking policy. Arnott, dePalma, and Lindsey (1992) and Anderson and dePalma (2004) examined the spatial pattern of parking over time, and how this is affected by various parking policies, when all drivers have the same desired arrival time at a common destination. Calthrop (2001a) presented a spatially homogeneous model characterizing the steady-state equilibrium of onand off-street parking, in which the time searching for on-street parking balances the higher fee associated with off-street parking. Calthrop (2001b) analyzed the optimal enforcement levels and parking meter fees for on-street parking. Arnott and Rowse (1999) focused on optimal on-street parking search strategy on an isotropic circular road with unsaturated parking, taking into account walking time. And Glazer and Niskanen (1992) considered a sequence of partial models to illustrate possible perverse results from the naïve application of parking policy. No papers in the literature, however, considers the congestion interaction on city streets between cars in transit and cars cruising for parking, which is the principal 
focus of this paper and its sequels.

\section{The Model}

We start with a thumbnail sketch of the model, and follow it with a formal description.

\subsection{Thumbnail description}

The model describes a city's downtown area as a spatially symmetric Manhattan network of identical, congested city streets. Traffic conditions remain unchanged over the period of the study. All travel is by car and all parking is on street. All trips are the same, and entail driving a fixed distance over downtown streets directly to a downtown destination, parking there immediately if a vacant parking spot is available and otherwise cruising round the destination block until a spot opens up, visiting the destination for a fixed period of time, and then exiting the system. The demand for trips is inversely related to the full trip price, which includes time and money costs.

Parking in the downtown area may be completely saturated. Travel speed on the roads depends on the street width and the proportion of curbside allocated to parking, as well as on the density of the two types of traffic - cars in transit and cars cruising for parking.

The model has its central characteristics that, under saturated parking conditions, the stock of cars cruising for parking adjusts to clear the market for parking, and that cars cruising for parking slow down traffic, and will be employed to explore how equilibrium traffic conditions are affected by exogenous parameters as well as policy, which includes parking pricing and the allocation of curbside to parking.

\subsection{Formal description}

Spatial symmetry is assumed to simplify the analysis. Blocks are square with sides of length $b$, streets are of width $W$, and $P_{\max }$ is the maximum possible number of on-street parking spaces per unit area. Throughout the paper, we shall ignore the complications that arise from the indivisibility of lanes of traffic ${ }^{2}$. Figure 1 portrays the geometry of the Manhattan street network.

\footnotetext{
${ }^{2}$ For concreteness, one may imagine that all streets are one way. This reduces the practical importance of the indivisibility problem but does not affect the analysis.
} 


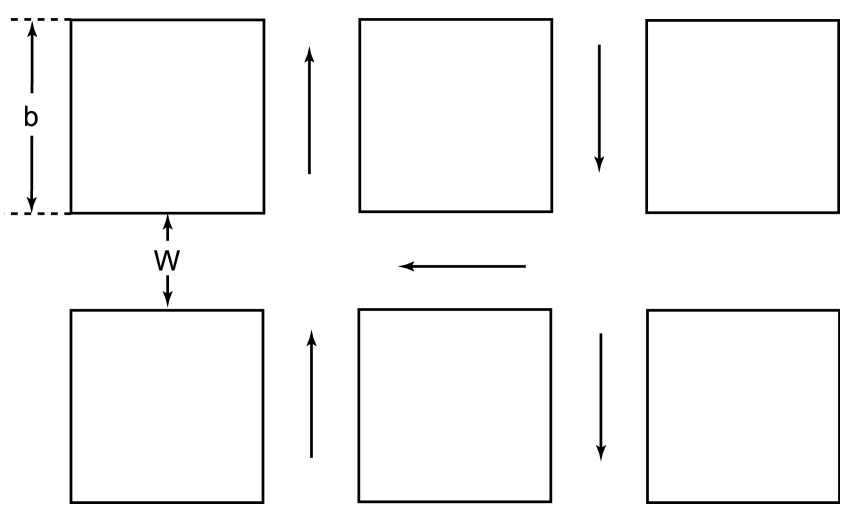

$$
\begin{aligned}
b & : \text { length and width of a block } \\
W & : \text { road width } \\
\rightarrow \quad & : \text { direction of traffic flow (one-way streets) }
\end{aligned}
$$

Figure 1: Manhattan geometry

Individuals are identical and risk neutral, basing their decisions on expected values. All travel is by car. Each trip originates from outside the downtown area and entails travel for a distance $m$ through the downtown area to a destination. Destinations are uniformly distributed over the downtown area, and parking may be saturated. An individual drives directly to the destination ${ }^{3}$, parks there immediately if a parking spot is available and otherwise circles the block cruising for parking until he finds a vacant parking $\operatorname{spot}^{4}$, stays at the destination for a period of time $l$ and then exits the downtown area. The time required to walk from the parking location to the destination is ignored. These assumptions permit a simple representation of traffic at the aggregate level in a saturated steady-state equilibrium.

Let $T$ be the pool or stock of individuals per unit area in transit to their destinations, $C$ be the pool of individuals per unit area cruising for parking, and $P$ be the stock of on-street

\footnotetext{
${ }^{3}$ Arnott and Rowse (1999) consider a model in which the city is located on the outside of a circle and in which parking is unsaturated. The individual decides, on the basis of the mean density of vacant parking spaces, how far from his destination to start cruising for parking, then takes the first vacant parking space, and then walks from there to his destination. With this parking strategy, there is no scope for learning.

In the model of this paper, taken literally, a driver could adopt a more sophisticated strategy than just circling the block since he knows that no parking spot can be occupied for a period greater than $l$. With a simple adaptation of the model, however - assuming that visit lengths are Poisson distributed with mean $l$ - circling the block is the optimal strategy. Since this adaptation does not alter the model's steady-state properties, the reader may choose this alternative specification and interpretation of the model. Later, to simplify analysis of the stability properties of the model, we assume that not only $l$ but also $m$ are Poisson distributed.

${ }^{4}$ For the analysis, it does not matter whether, as they are vacated, parking spots are allocated to cruisers for parking on a FIFO or on a random basis, but it is natural to assume random allocation, in which case from the perspective of a cruiser for parking obtaining a parking spot is generated by a Poisson process with arrival rate $P /(C l)$.
} 
parking spaces per unit area, which equals the pool of individuals parked per unit area when parking is saturated.

The rate of entry into the network per unit time-area, or equivalently the trip demand per unit time-area is $D$. Trip demand depends on the full price of a trip, which equals the cost of in-transit travel time plus the cost of time spent cruising for parking plus the expenditure for on-street parking. Let $t$ denote the in-transit travel time per unit distance, which the individual treats as exogenous but is determined by how the congested roads are, as part of the overall equilibrium.

Consider each of the pools in turn. The rate of change of the size of the in-transit pool equals the entry rate, $D$, minus the exit rate, $E$. Thus,

$$
\dot{T}(u)=D(u)-E(u),
$$

where $u$ denotes time. With saturated parking the rate of change of the size of the cruisingfor-parking pool equals the entry rate into cruising-for-parking pool, which equals the exit rate from the in-transit pool, minus the exit rate from the cruising-for-parking pool, $Z$.

$$
\dot{C}(u)=E(u)-Z(u)
$$

In steady $\operatorname{state}^{5}$, the exit rate from the in-transit pool equals the pool size divided by an individual's time in the pool, so that (1) becomes

$$
D=\frac{T}{m t}
$$

and with saturated parking the exit rate from the cruising-for-parking pool equals the exit rate from parking so that (2) becomes

$$
\frac{T}{m t}=\frac{P}{l}
$$

These steady-state relationships with saturated parking are displayed in Figure 2.

We refer to (3) as the in-transit pool steady-state condition and to (4) as the cruising-forparking pool steady-state condition.

\footnotetext{
${ }^{5}$ Later, when we investigate stability, we modify the model slightly so that $m$ is Poisson distributed in the population, in which case $T /(m t)$ is the exit rate from the in-transit pool away from the steady-state equilibrium as well as at the equilibrium.
} 


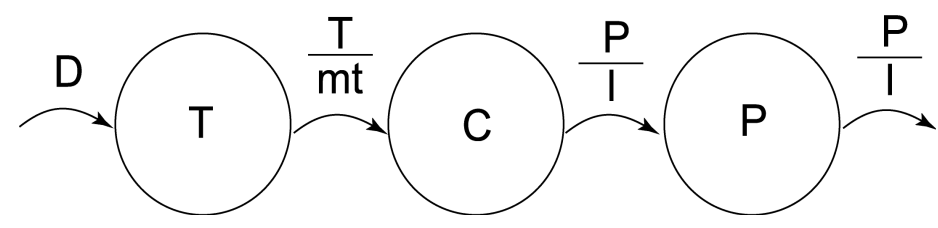

$T \quad$ Stock of cars in transit (per unit area)

$C \quad$ Stock of cars cruising for parking

$P \quad$ (On-street) parking spaces $=$ stock of cars parked

$D \quad$ Demand inflow

$\frac{T}{m t} \quad$ Exit rate from in-transit pool

$=$ entry rate into cruising-for-parking pool

$\frac{P}{l} \quad$ Exit rate from cruising-for-parking pool

$=$ entry rate into parking pool

$=$ exit rate from parking pool

Figure 2: Steady-state stocks and flows with saturated parking

The steady-state full trip price, $F$, is

$$
F=\rho\left(m t+\frac{C l}{P}\right)+f l
$$

where $\rho$ is the value of time and $f$ the on-street parking fee per unit time; the full trip price is the sum of the in-transit travel time cost, the expected cruising-for-parking time cost, and the money cost of on-street parking at the destination.

Two more equations are needed to complete the characterization of a saturated steady-state equilibrium. The first is the steady-state flow demand function, which is sensitive to the full price and is smooth:

$$
D=D(F) ; \quad D(0)=\infty, \quad D(\infty)=0, \quad D^{\prime}<0
$$

The second equation describes the $\operatorname{smooth}^{6}$ congestion technology ${ }^{7}$ :

$$
t=t(T, C, W, P)
$$

where $t_{T}>0, t_{C}>0, t_{W}<0, t_{P}>0, t(0,0, W, P)>0, \lim _{P \rightarrow P_{\max }} t(T, C, W, P)=\infty$, and $t$

\footnotetext{
${ }^{6}$ We should keep in mind, however, that there may be a jam density (as in the Greenshield's relation (1935)) and that the function $t$ may not be well defined if the density exceeds this level.

${ }^{7}$ In the numerical examples, we shall particularize this function, assuming, as is standard, that travel time is a convex function of the volume-capacity ratio: $\hat{t}=\hat{t}\left(\frac{V}{\omega}\right)$ where $\hat{t}^{\prime}>0, \hat{t}^{\prime \prime}>0 ; V=V(T, C)$ with $V_{T}>0$ and $V_{C}>0$ is the effective volume or density of traffic, and $\omega(W, P)$ is the effective capacity, with $\omega_{W}>0$ and $\omega_{P}<0$.
} 
is convex in $T, C$, and $P$.

\section{Analysis of Saturated Steady-state Equilibrium}

Substituting (5), (6) and (7) into (3) and (4) gives the following two equations in two unknowns, $T$ and $C$ :

$$
\begin{aligned}
D\left(\rho\left((T+C) \frac{l}{P}\right)+f l\right) & =\frac{P}{l} \\
\frac{T}{m t(T, C, W, P)} & =\frac{P}{l} .
\end{aligned}
$$

Definition 1 A saturated, steady-state equilibrium is a pair $(T, C)$ with $T>0, C \geq 0$, that solve (8) and (9).

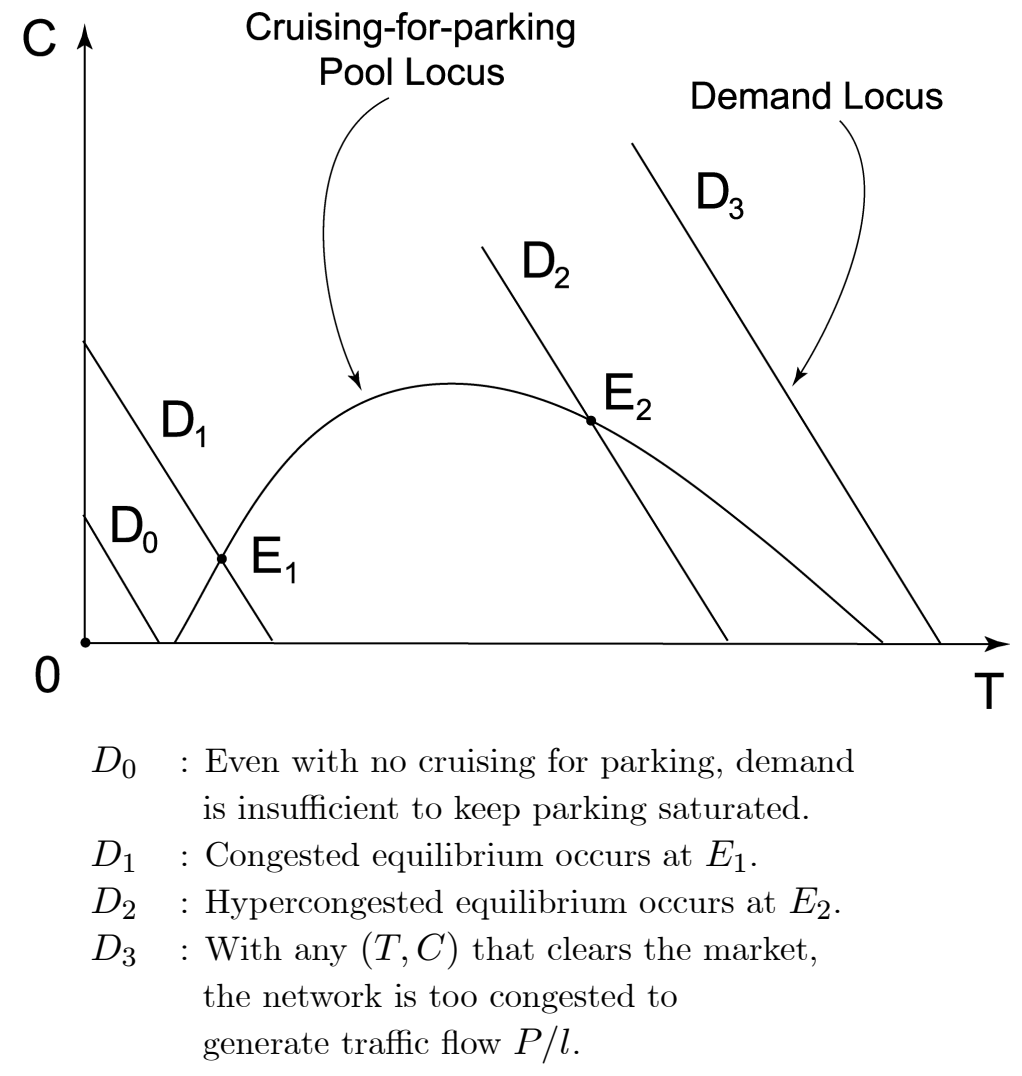

Figure 3: Saturated, steady-state equilibrium in T-C space for different levels of demand

Figure 3 plots these two loci in the positive orthant of $T-C$ space. We refer to (8) as the demand locus, (9) as the cruising-for-parking-pool locus, and $P / l$ as steady-state throughput 
or flow. It is evident that (8) has a slope of -1 . Since the partial derivatives of $t$ with respect to $T$ and $C$ are continuous, (9) is continuous. Its slope is

$$
\left.\frac{\partial C}{\partial T}\right|_{(9)}=\frac{\frac{t}{T}-t_{T}}{t_{C}} .
$$

\subsection{Uniqueness}

(A.1) A car cruising for parking contributes more to congestion than a car in transit $\left(t_{C}>t_{T}\right)^{8}$.

Lemma 1 (Uniqueness) Assume (A.1) holds. Then, if equilibrium exists it is unique.

Proof. In the positive orthant, the slope of the cruising-for-parking pool locus is greater than that of the demand locus. If, therefore, the two loci intersect in the positive orthant, they do so only once there.

\subsection{Existence}

We now consider the conditions for the existence of a saturated, steady-state equilibrium. Consider (9) with $C=0$. The equation is solved for those densities of in-transit traffic corresponding to traffic flow levels of $P / l$. One circumstance under which a saturated equilibrium does not exist occurs when the road's flow capacity - defined as $\max _{T} \frac{T}{m t(T, 0, W, P)}$ falls short of $P / l$. In this case, if an equilibrium exists it entails parking being unsaturated ${ }^{9}$. In terms of Figure 3, this low flow capacity situation occurs when the cruising-for-parking pool locus disappears. Another occurs when, even with no cars on the road, the quantity of trips demanded falls short of $P / l$. In terms of Figure 3, this low demand situation occurs when the demand locus lies everywhere to the left of cruising-for-parking locus. Yet another occurs when demand is so high that all $(T, C)$ on the demand locus would generate so much congestion that a steady-state throughput of $P / l$ cannot be achieved. We refer to this as the high demand situation.

\footnotetext{
${ }^{8}$ Rouwendal, Rietveld and Verhoef (1999) analyzes the congestion interaction between slow- and fastmoving cars on a single-lane road. As one would expect, one slow-moving car when all other cars are moving fast adds considerably to congestion. But also, one fast-moving car when all other cars are moving slowly adds considerably to congestion. The situation here is analogous. One car cruising for parking when all other cars are in transit creates considerable congestion, but so too does one car in transit when all other cars are cruising for parking. Thus, the congestion technology is in fact more complicated than is assumed.

${ }^{9}$ We shall investigate this when we discuss stability.
} 
(A.2) Road flow capacity is higher than the steady-state throughput $\left(\max _{T} \frac{T}{m t(T, 0, W, P)}>\frac{P}{l}\right)$.

(A.3) $\frac{T}{m t(T, 0, W, P)}=\frac{P}{l}$ has two $\operatorname{roots}^{10}, T^{\prime}$ and $T^{\prime \prime}, T^{\prime}<T^{\prime \prime}$.

(A.4) $\left.T^{\prime} \leq\left(D^{-1}\left(\frac{P}{l}\right)-f l\right)\right) \frac{P}{l \rho} \leq T^{\prime \prime}$.

Theorem 1 (Existence) Iff (A.2), (A.3) and (A.4) holds, a saturated steady-state equilibrium exists.

Proof. From (A.2) and (A.3) and the continuity of $\frac{T}{m t(T, C, W, P)}$ in $T$ and $C$, the cruisingfor-parking pool locus is in the positive orthant for $T \in\left[T^{\prime}, T^{\prime \prime}\right]$. From (A.4), the continuous demand locus intersects the $C=0$ line below the cruising-for-parking locus and the $T=0$ line above it.

Corollary 1 If (A.1)-(A.4) hold, then there exists a unique saturated steady-state equilibrium.

\subsection{Comparative statics}

The comparative static properties of the saturated steady-state equilibrium are given in Table 1. The comparative static properties with respect to $\rho, m, W$, and parameters which shift either the demand function or the congestion function but not both can be simply derived from Figure 3 since each of these parameter changes affects only one of the loci. The only remaining parameters, which affect both of the loci, are $P$ and $l$.

Let us first examine the effect of a small increase in demand - an upward shift in the demand locus. If equilibrium occurs on an upward-sloping portion of the cruising-for-parking-pool locus, the increase in demand causes an increase in both $C$ and $T$; if equilibrium occurs on a downward-sloping portion of the locus, the increase in demand causes an increase in $T$ and $C+T$, but a decrease in $C$. From (10), it follows that the cruising-for-parking-pool locus is upward sloping if the elasticity of travel time with respect to $T$ is less than one, and downward sloping if this elasticity is greater than one. With some abuse of terminology ${ }^{11}$,

\footnotetext{
${ }^{10}$ This assumption is implied by (A.2) and the convexity of $t$ in $T$ and $C$.

${ }^{11}$ Simple traffic flow models are constructed using two equations. The first relates velocity to density: $v=\Delta(V)$. The second is the fundamental identity of traffic flow, that flow equals velocity times density, $q=V v$. Combining these two equations gives $q=\Delta^{-1}(v) v$, the graph of which is referred to as the flowvelocity curve. One particularly simple specification — Greenshield's Relation (1935) — is that velocity is a negative, linear function of density, with $\bar{v}$ being free-flow velocity and $V_{j}$ being jam density; with this
} 


\begin{tabular}{lllllllll}
\hline \hline & $\rho$ & $W$ & $P$ & $m$ & $l$ & $f$ & $\xi^{1}$ & $\gamma^{2}$ \\
\hline$T$ & - & - & $?^{5}$ & + & $?^{5}$ & - & + & - \\
$\frac{T l}{P}$ & - & - & $?^{5}$ & + & $?^{5}$ & - & + & - \\
$C$ & $?^{3}$ & + & $?^{5}$ & - & $?^{5}$ & $?^{3}$ & $?^{4}$ & + \\
$\frac{C l}{P}$ & $?^{3}$ & + & $?^{5}$ & - & $?^{5}$ & $?^{3}$ & $?^{4}$ & + \\
$T+C$ & - & 0 & $?^{5}$ & 0 & $?^{5}$ & - & + & 0 \\
$\frac{(T+C) l}{P}$ & - & 0 & - & 0 & $?^{5}$ & - & + & 0 \\
\hline \hline
\end{tabular}

Notes:

1. An increase in $\xi$ corresponds to an increase in demand at all levels of the full trip price.

2. An increase in $\gamma$ corresponds to a decrease in $t$ for every $(T, C, W, P)$.

3. Has sign of $1-E_{t: T}$.

4. Has sign opposite to that for corresponding derivative with respect to $\rho$.

5. Sign depends on, inter alia, the demand elasticity.

Table 1: Comparative static properties of the model

we say that travel is congested in the former situation and hypercongested in the latter. Consider congested travel. Increase demand, holding fixed the stock of cars cruising for parking. From (8), the full price of travel must increase to restore equilibrium. With $C$ and $f$ fixed, this requires that $T$ increase. Since travel is congested, an increase in $T$ results in a less-than-proportional increase in $t$. To continue to satisfy (9), $C$ must increase. The other comparative static results, except those for $P$ and $l$, can be obtained by analogous argument.

An increase in $l$ causes the cruising-for-parking-pool locus to shift up; the increase in $l$ causes the throughput to fall, which requires that $C$ increase for any level of $T$. The effect of the increase in $l$ on the demand locus is ambiguous. The fall in throughput requires that the quantity of trips demanded fall, but the increase in $l$ causes the quantity of trips demanded to fall directly. Which effect dominates depends on the demand elasticity; if, as is realistic, the demand elasticity is less than one, $C+T$ must rise to restore equilibrium, which entails an upward shift in the demand locus. An increase in $P$ causes the cruising-forparking pool locus to shift down; for a given level of $T$, with increased road space devoted to parking, the increase in throughput requires that $C$ fall. The effect of the increase in $P$ on the demand locus is ambiguous. The increase in throughout requires that the quantity

specification, the flow-velocity curve is a parabola. If the equilibrium occurs on a negatively-sloped portion of the flow-velocity curve, so that an increase in flow corresponds to a decrease in speed, travel is said to be congested, while if the equilibrium occurs on a positively-sloped portion of the curve, so that an increase in flow corresponds to an increase in speed, travel is said to be hypercongested (this terminology is due to Vickrey). Congested equilibria correspond to freely-flowing traffic, and hypercongested equilibria to traffic jam situations. 
of trips demanded increase, but the increase in $P$ causes the quantity of trips demanded to increase directly, and which effect dominates depends on the demand elasticity.

Since raising the parking fee when parking is saturated, and when therefore there is cruising for parking, has no effect on the equilibrium trip price, it is perhaps intuitive that an increase in parking fee revenue reduces cruising-for-parking costs dollar for dollar. The incorrectness of this intuition can be seen from Figure 3. Raising the parking fee shifts the demand locus to the left. If the initial equilibrium is congested, the equilibrium $T$ and $C$ both fall; if it is hypercongested, the equilibrium $T$ and $T+C$ fall but the equilibrium $C$ rises. Thus, an increase in the parking fee can increase cruising for parking. The correct intuition is that parking fee revenue replaces the sum of in-transit travel costs and cruising-for-parking costs dollar for dollar.

\subsection{Steady-state social optimum}

The social benefit from travel per unit area-time is an increasing function of the steady-state throughput, and its derivative gives the marginal benefit. The social cost per unit area-time is the aggregate cost of travel time per unit area-time, which equals the value of time times the number of cars in transit and cruising for parking per unit area at that point in time. Social surplus (per unit area-time) equals social benefit minus social cost.

Definition 2 The short-run saturated steady-state social optimum is the pair $\left(T^{*}, C^{*}\right)$ satisfying (9) such that social surplus, given by $B\left(\frac{P}{l}\right)-\rho(C+T)$, is maximized.

Thus, this social optimum is the solution to

$$
\max _{C, T} B\left(\frac{P}{l}\right)-\rho(C+T) \quad \text { s.t. } \quad \frac{T}{m t(T, C, W, P)}=\frac{P}{l} .
$$

The maximization problem reduces to the minimization of travel time cost, which is achieved with $C^{*}=0$ and $T$ equal to the lower value of $T$ which solves $T /(m t(T, 0, W, P))=P / l$. From an initial situation with saturated parking and no cruising for parking, this social optimum can be decentralized by setting $f$ at such a level that $D\left(\rho T^{*}+f l\right)=P / l$. The corresponding parking fee is

$$
f^{*}=\frac{D^{-1}\left(\frac{P}{l}\right)-\rho T^{*}}{l} .
$$

The above reasoning identifies the short-run, saturated steady-state social optimum and indicates how it can be decentralized. But is the short-run, saturated, steady-state social optimum necessarily the overall short-run, steady state social optimum? Suppose it were 
otherwise. Since a given throughput can be achieved at lowest cost with no cruising for parking, the short-run steady-state social optimum would solve

$$
\max _{S, T} B\left(\frac{S}{l}\right)-\rho T \quad \text { s.t. } \quad \frac{T}{m t(T, 0, W, P)}-\frac{S}{l}=0
$$

where $S / l$ is the steady-state throughput and $S$ the stock of occupied parking spaces at the social optimum. If demand is sufficiently high that the $S$ that solves this maximization problem exceeds $P$, then the parking availability constraint binds and the steady-state optimum is saturated (the proof of this uses $t_{T T}<0$.). Thus:

Proposition 1 If demand is "sufficiently high" (as defined just above), the short-run, steady-state social optimum entails saturated parking and no cruising for parking. This allocation can be decentralized by setting the parking fee according to (12).

Some remarks are in order. First, the above analysis assumes that the marginal cost of public funds equals one and that there are no administrative costs in the collection of parking fee revenue. The analysis can be straightforwardly modified to account for these complications, which may be practically important. Second, when there is cruising for parking in steady-state equilibrium, the aggregate efficiency gains from raising the parking fee to the optimal level are at least as high as the aggregate cruising-for-parking costs in the initial equilibrium. This can be seen from Figure 3. Raising the parking fee to the optimal level from an initial saturated equilibrium shifts the demand locus to the left, to the point where it just continues to intersect the cruising-for-parking locus, with $C=0$. The aggregate efficiency gains from this increase in the parking fee equal the reduction in the value of $\rho(C+T)$ from the initial equilibrium to the optimum. Third, we claim that Proposition 1 is essentially an efficiency result, and so extends to the situation where individuals differ in terms of the value of time, visit duration, and trip length, as long as lump-sum transfers are feasible. When they are not, some loss in efficiency might in principle be justified for an improvement in equity. Since, however, few of the truly needy drive cars, equity considerations in this context are likely of secondary importance.

\subsection{Diagrammatic characterization of the equilibrium and optimum}

It will aid intuition to recast the model in terms of the standard traffic congestion diagram in flow-price space, which is based on a model of flow congestion with no parking capacity constraint. In that diagram, short-run (with road capacity fixed) equilibrium in the absence of a congestion toll occurs where the user cost curve intersects the demand curve, while the 
short-run social optimum (which can be decentralized with the optimal toll) occurs where the short-run marginal social cost curve intersects the demand curve. In the saturated parking model presented here, the demand curve is well defined. On the supply side, however, the parking model differs from the standard model in two respects. First, user cost and marginal social cost depend not only on the throughput but also on the amount of cruising for parking, which is endogenous. Second, there is a parking capacity constraint, that the equilibrium flow cannot exceed that permitted by the parking available, and with saturated parking must equal it. When the parking constraint binds, the causality is also different. The equilibrium full price, $F^{e}$, and flow are determined by the intersection of the demand curve and the parking capacity constraint. The equilibrium stocks of cars cruising for parking and in-transit are consistent with these equilibrium values. This subsection presents the results derived in the previous subsection for the short-run equilibrium and optimum, using this diagrammatic apparatus, on the assumption that demand is sufficiently high that in the absence of a parking fee, there exists an equilibrium with saturated parking. Recall that, under our assumptions on the form of the travel time function, if there is an equilibrium with saturated parking it is the unique equilibrium with saturated parking.

Turn to Figure 4, which is in price (full price) - quantity (steady-state flow) space. Draw in the demand curve and the parking capacity constraint. By assumption, in the absence of a parking fee, the saturated parking equilibrium occurs at the point of intersection of the demand curve and the parking constraint, point $E$ in the diagram. It will prove useful to define short-run user cost and short-run marginal social cost in the absence of cruising for parking.

Definition 3 The short-run user cost function $\left(u c^{s r}\right)$ is the (congested) steady-state intransit user cost in the absence of cruising for parking, $\rho m t$, as a function of the steady-state flow, $q$, and with $W$ and $P$ held fixed:

$$
u c^{s r}(q ; P)=\rho m t(\hat{T}(q ; P), 0, W, P)
$$

where $\hat{T}(q ; P)$ is defined implicitly by

$$
\hat{T}(q ; P)=\min \left[\text { solution wrt } T \text { of } q=\frac{T}{m t(T, 0, W, P)}\right] \text {. }
$$

Thus, $\hat{T}(q ; P)$ is the stock of cars in-transit consistent with congested flow $q$ when parking availability is $P$, and $u c^{s r}(q ; P)$ is the corresponding (in-transit) user cost. 


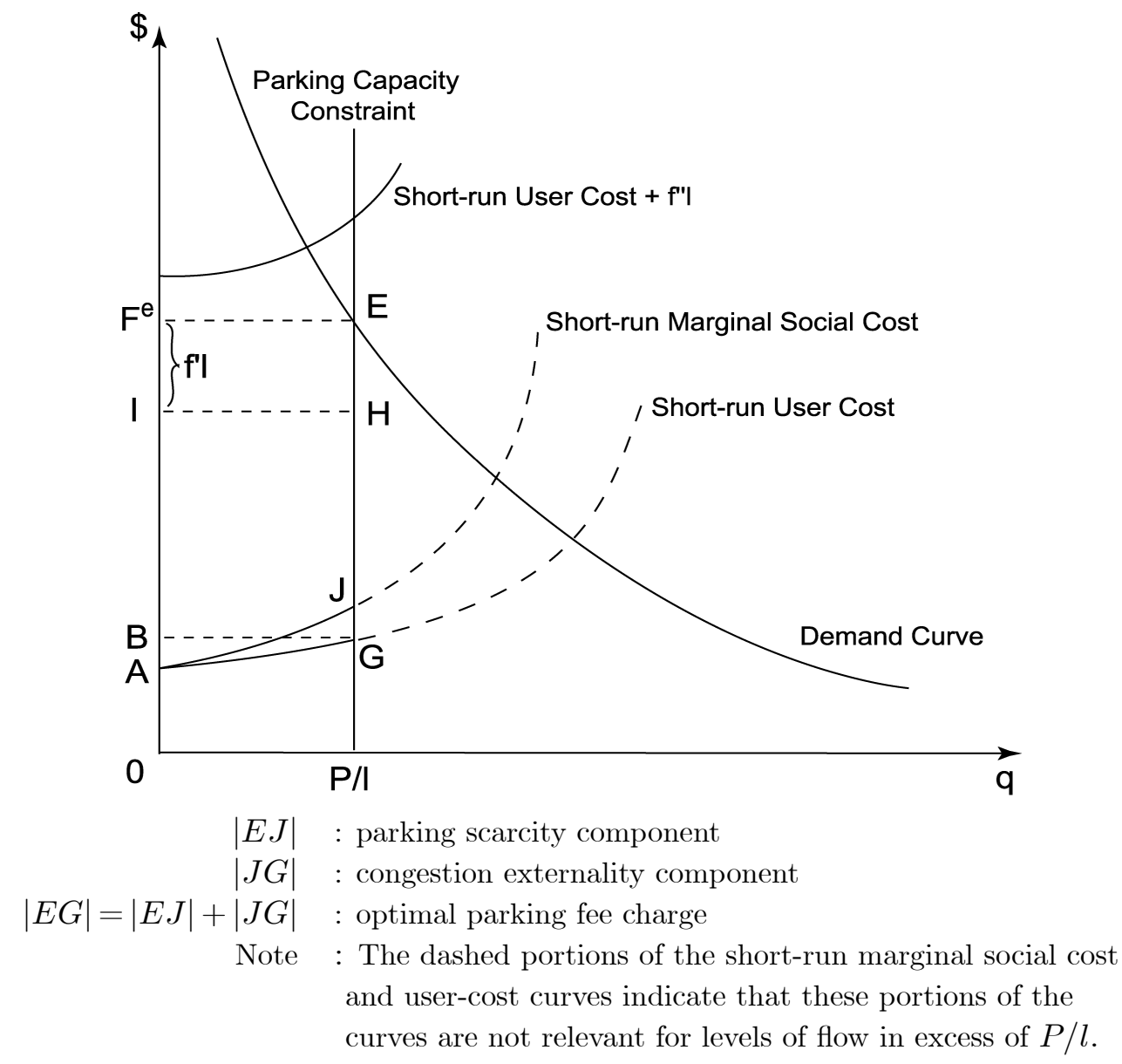

Figure 4: Steady-state equilibrium with saturated parking and the parking fee set at the optimal level

Definition 4 The short-run marginal social cost function $\left(m s c^{s r}\right)$ is the increase in the aggregate, steady-state (congested) in-transit flow social cost, in the absence of cruising for parking, resulting from a unit increase in steady-state flow, as a function of steady-state flow, with $W$ and $P$ held fixed:

$$
\begin{aligned}
m s c^{s r}(q ; P) & =\frac{\partial \rho \hat{T}}{\partial q}=\frac{\frac{\partial \rho \hat{T}}{\partial \hat{T}}}{\left.\frac{\partial q}{\partial \hat{T}}\right|_{(15)}} \\
& =\frac{\rho m t}{1-\frac{t_{\hat{T}} \hat{T}}{t}} .
\end{aligned}
$$

Several comments are in order. First, $\hat{T}(q ; P)$ is so defined in order to impose the condition that the social optimum entails congested rather than hypercongested flow. Second, while 
the $u c^{s r}$ and $m s c^{s r}$ functions are well defined for levels of steady-state flow exceeding $P / l$, the analysis will use only those portions of the functions with $q \leq P / l$. Third, the ratio of $u c^{s r}$ to $m s c^{s r}$ at a particular level of steady-state flow equals one minus the elasticity of $t$ with respect to $\hat{T}(q ; P)$.

The short-run, steady-state social optimum occurs at point $E$ in the diagram, and entails no cruising for parking and congested rather than hypercongested travel. This optimum is decentralized ${ }^{12}$ with a parking fee $f^{*}$ such that $f^{*} l$ equals the vertical distance between $E$ and the point of intersection of the short-run user cost curve and the parking capacity constraint, $G$. With this fee, there is saturated parking, no cruising for parking, a full price of $F^{e}$, and a flow rate of $P / l$. The efficient parking charge has two components. The first, $|J G|$ in the diagram, is the flow congestion externality cost, the difference between the short-run marginal social cost and short-run user cost. The second, $|E J|$ in the diagram, is the parking externality cost or parking scarcity rent. Social surplus with this level of parking capacity is given by the area under the demand curve up to the parking capacity constraint, $P / l$, minus the area under $|B G|$; this is also equal to the area under the demand curve minus the area under the short-run marginal social cost curve up to $P / l$. Thus, the parking scarcity rent is the increase in social surplus from relaxing (9) by one unit without altering the amount of curbside allocated to parking.

Suppose that the parking fee is set below $f^{*}$, at say $f^{\prime}$. Then there is cruising for parking in the saturated equilibrium. Since we defined the short-run user cost and marginal social cost curves in the absence of cruising for parking, they no longer apply. The equilibrium full price and flow are the same as with $f$ set at $f^{*}$. Since the full price equals the private cost, $\rho l(C+T) / P$, plus the parking charge, $f^{\prime} l$, social surplus is now the area under the demand curve up to the parking capacity constraint minus the area under $|I H|$ Compared to the equilibrium with the optimal parking fee, social surplus has fallen by the same amount as has revenue. Suppose, alternatively, that the parking fee is set above $f^{*}$, at say $f^{\prime \prime}$. The parking capacity constraint no longer binds - parking becomes unsaturated and cruising for parking disappears. An equilibrium ${ }^{13}$ occurs at the point of intersection of the short-run user cost curve (which is now applicable since there is no cruising for parking), shifted up by the amount of the parking charge, $f^{\prime \prime} l$, and the demand curve, and social surplus is lower than with the parking fee, $f^{*}$.

The above discussion applies to the situation portrayed in Figure 4, in which the point $E$

\footnotetext{
${ }^{12}$ But there may also be unsaturated, hypercongested equilibria associated with the parking fee $f^{*}$. This possibility can be displayed using a diagram similar to panel $B$ of Figure 6 .

${ }^{13}$ We say "an" equilibrium since there may be multiple points of intersection of the short-run user cost curve, generalized to admit hypercongestion, and the demand curve. This possibility can be displayed using a diagram similar to panel $B$ of Figure 6 .
} 
lies to the left of the intersection of the short-run marginal social cost curve and demand curve. Suppose instead that the point $E$ lies between the intersection points of the shortrun marginal social cost and short-run user cost curves, and the demand curve. The social optimum then entails unsaturated parking, while in the absence of a parking fee there is a saturated parking equilibrium. If the point $E$ lies to the right of the intersection point of the short-run user cost curve and the demand curve, both the social optimum and the equilibrium in the absence of a parking fee entail unsaturated parking.

\subsection{Optimal parking capacity}

In this subsection we investigate social optima and equilibria when the government chooses parking capacity to maximize social surplus.

Definition 5 The long-run, steady-state social optimum is the triple $\left(T^{*}, C^{*}, P^{*}\right)$ satisfying $T /(m t) \leq P / l$ such that social surplus is maximized.

Suppose that this optimum entails unsaturated parking, so that the inequality constraint does not bind and there is no cruising for parking. Since this supposed optimum entails congested rather than hypercongested travel, the same steady-state flow can be achieved at lower social cost by lowering the amount of curbside allocated to parking. Thus, the longrun, steady-state social optimum entails the inequality constraint binding, implying that parking is saturated. Suppose that this optimum entails cruising for parking. The same steady-state flow can be achieved at lower social cost by lowering the stock of cars cruising for parking. Using these two results, we may adopt a less primitive but more operational definition of the social optimum.

Definition $5^{\prime}$ The long-run, steady-state social optimum is the pair $\left(T^{*}, P^{*}\right)$, along with $C^{*}=0$, satisfying (9) such that social surplus, given by $B(P / l)-\rho T$, is maximized.

Definition 6 Long-run marginal social cost $\left(\mathrm{msc}^{l r}\right)$ is the increase in aggregate in-transit cost per unit time, $\rho T$, with a unit increase in steady-state congested flow, varying $P$ so that parking remains saturated $(P=q l)$ without cruising for parking:

$$
m s c^{l r}(q)=\left.\frac{\partial \rho \tilde{T}}{\partial q}\right|_{(9)}=\left.\rho l \frac{\partial \tilde{T}}{\partial P}\right|_{(9)}
$$

where $\tilde{T}(q)$ is the lower value of $T$ which solves $q=\tilde{T} /(m t(\tilde{T}, 0, W, q l))$ (or equivalently $P / l=\tilde{T} /(m t(\tilde{T}, 0, W, P)))$. 
There are three components to this cost. The first derives from the increase in steady-state flow, holding travel speed fixed; the second, from the decrease in travel speed due to the increased flow; and the third, from the decrease in travel speed due to the increased amount of curbside allocated to parking. The increase in the stock of cars in transit due to these three effects is obtained by total differentiation of (9), holding $C$ fixed at 0 , which yields

$$
\left.\frac{\partial \tilde{T}}{\partial P}\right|_{(9)}=\frac{\tilde{T}}{P}\left(\frac{1+\frac{P t_{P}}{t}}{1-\frac{\tilde{T} t_{\tilde{T}}}{t}}\right)
$$

Let $\tilde{P} / l$ be the maximum technologically feasible level of flow. We have already assumed that $D^{-1}(0)=\infty$. The additional assumption that $m s c^{l r}(0)$ is finite rules out the possibility that $P^{*}=0$. Also, since $m s c^{l r}(\tilde{P})=\infty$, the finiteness of demand at this level of flow rules out the possibility that $P^{*}=\tilde{P}$. Thus, $P^{*}$ is an element of $(0, \tilde{P})$. Since, furthermore, the demand and $m s c^{l r}$ functions are continuous over this interval, the steady-state social optimum occurs at a point of intersection of these functions. Finally, since we have assumed that the demand function is decreasing in $q$ and since our assumptions on $t(\cdot)$ imply that $m s c^{l r}$ is increasing in $q$, the point of intersection of these functions is unique. Thus, the socially optimal level of parking capacity, $P^{*}$, occurs at the unique point of intersection of the demand and $m s c^{l r}$ functions, and satisfies

$$
\max _{T, P} B\left(\frac{T}{m t}\right)-\rho T \quad \text { s.t. } \quad(9) \quad \text {. }
$$

Definition 7 The long-run user cost is

$$
u c^{l r}(q)=\operatorname{\rho mt}(\tilde{T}(q), 0, W, q l)
$$

Figure 5 displays the long- and short-run marginal social cost functions, and the short-run user cost function as well as the demand function, in full price-flow space. The long-run social optimum occurs at $\theta$, the point of intersection of the demand and $m s c^{l r}$ functions. As in the short run, long-run marginal social cost may be decomposed into long-run user cost (which equals the short-run user cost at $P=P^{*}$ ), the congestion externality cost, and the parking externality cost. At the long-run social optimum, the congestion externality cost equals the vertical distance $|J G|$ and the parking externality cost the distance $|\theta J|$.

The first-best optimum can be decentralized by setting $P=P^{*}$ and a parking fee 


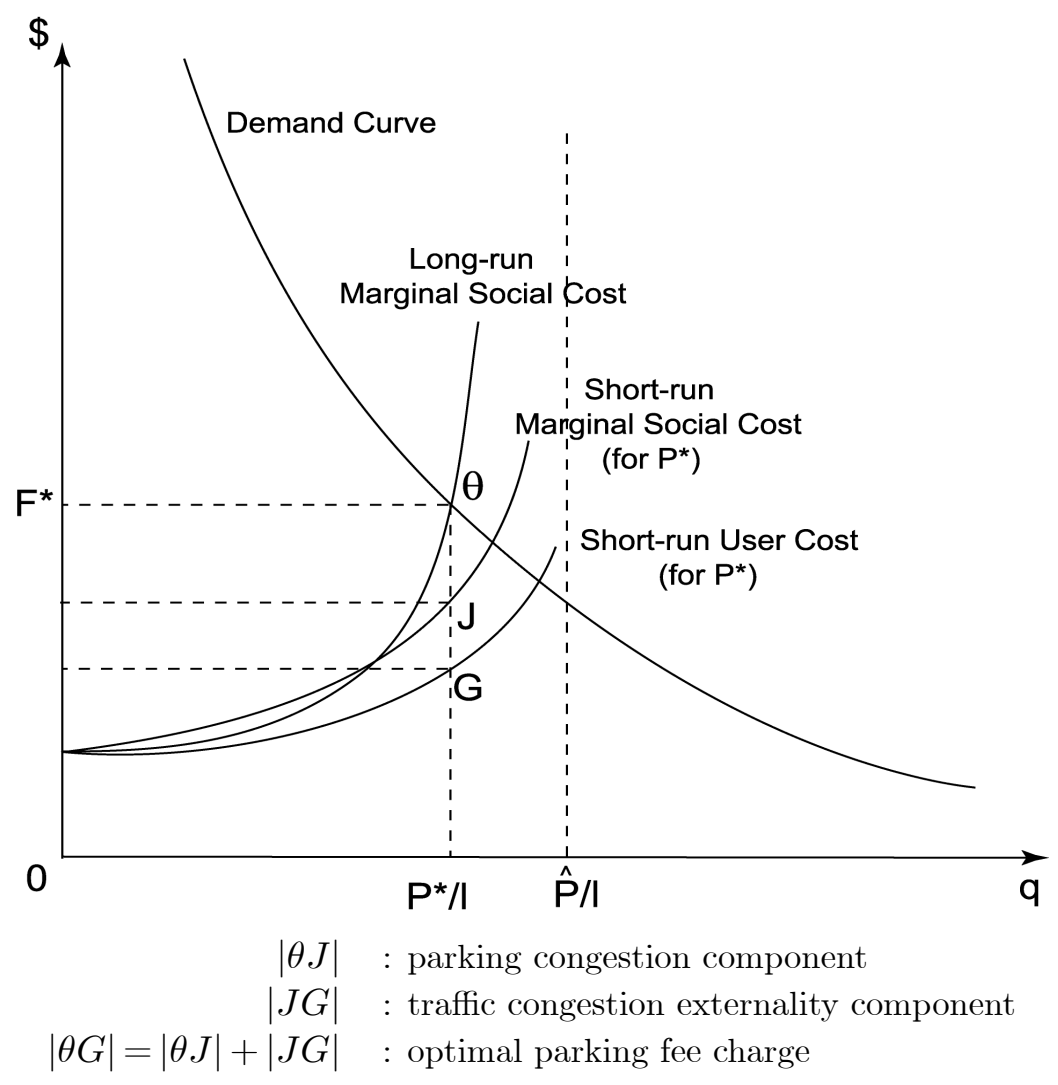

Figure 5: First-best optimum

$$
\begin{aligned}
f_{1}^{*} & =m s c^{l r}\left(\frac{P^{*}}{l}\right)-u c^{l r}\left(\frac{P^{*}}{l}\right) \\
& =m s c^{l r}\left(\frac{P^{*}}{l}\right)-u c^{s r}\left(\frac{P^{*}}{l} ; P^{*}\right) .
\end{aligned}
$$

Thus, we have:

Proposition 2 The first-best level of parking capacity solves (19). This corresponds to the level of steady-state flow at which the demand curve intersects the long-run marginal social cost curve. In the first-best allocation, parking is saturated and there is no cruising for parking. The first-best allocation is achieved by setting parking capacity at its first-best level and the parking fee according to (21).

The observant reader will have noticed that the relationship between short-run and longrun cost curves, according to our definitions, do not accord with those in conventional cost theory. The conventional long-run average cost curve is defined as the lower envelope of the 
corresponding short-run average cost curves, each defined for a particular level of capacity. Here, in contrast, long-run costs are defined as the costs which obtain when capacity is varied as flow is varied so as to satisfy the saturated parking constraint, that $q=P / l$. According to the conventional definition, short-run and long-run marginal social cost coincide at the optimal allocation. According to our definitions, the area under the short-run marginal social curve up to the optimal level of flow and with optimal parking capacity equals the area under the long-run marginal social curve up to the optimal level of flow. This equality corresponds to two different ways of calculating total social cost at the social optimum. The first is to hold constant parking capacity at $P^{*}$ and then to add up the increments to social cost from increasing flow unit by unit. The second is to add up the increments to social cost from increasing flow unit by unit, continually adjusting the level of parking so that it remains saturated.

Now consider the second best.

Definition 8 The second-best optimum conditional on a non-optimal level of the parking fee is defined as the triple $\left(T^{* *}\left(f^{\prime}\right), C^{* *}\left(f^{\prime}\right), P^{* *}\left(f^{\prime}\right)\right)$ satisfying (8) and (9) that maximizes social surplus.

There may be multiple equilibria corresponding to a particular $f^{\prime}$ and $P$. The definition implies that determination of the second-best optimum entails comparing the lowest cost (and hence entailing congested rather than hypercongested flow) equilibrium for each $\left(f^{\prime}, P\right)$ as $P$ is varied. Determination of second-best optimal parking capacity is surprisingly easy, at least conceptually.

Proposition 3 Second-best optimal parking capacity (when the parking fee is set at a nonoptimal level, $f^{\prime}$ ) is such that cruising for parking is eliminated but parking remains saturated.

Proof. Start off with a level of parking capacity for which equilibrium is saturated and there is cruising for parking. Increase parking capacity incrementally. This causes the equilibrium to move down the demand curve. Social surplus equals consumer surplus plus parking revenue, both of which are increased by the movement down the demand curve. This argument establishes the desirability of increasing parking capacity incrementally when the equilibrium entails cruising for parking. Now start off with a level of parking capacity for which the equilibrium is unsaturated (and hence involves no cruising for parking) and so occurs at the point of intersection of the short-run user cost curve for this level of 
parking capacity, shifted up by $f^{\prime} l$, and the demand curve. Now decrease parking capacity. This causes the short-run user cost curve to shift down, increasing equilibrium flow, and hence increasing both parking revenue and consumer surplus. This argument establishes the desirability of decreasing parking capacity incrementally when the equilibrium is unsaturated. The second-best optimal parking capacity is therefore that where equilibrium is on the borderline between saturated and unsaturated parking - saturated but with no cruising for parking.

Corollary 2 The second-best optimum with parking fee $f^{\prime}$ occurs at the point of intersection of the long-run user cost curve, shifted up by $f^{\prime} l$, and the demand curve.

Proof. The long-run user cost function gives the locus of user cost as a function of flow for which there is saturated parking and no cruising for parking. Thus, the point of intersection of the long-run user cost function, shifted up by $f^{\prime} l$, and the demand curve, gives the only allocation at which equilibrium is achieved and the necessary conditions for the second-best optimum given in Proposition 3 are satisfied.

We now investigate the relationship between first- and second-best optimal parking capacities.

Proposition 4 Second-best optimal parking capacity is less than/equal to/greater than first-best optimal parking capacity according to whether the on-street parking fee is greater than/equal to/less than the first-best on-street parking fee.

Proof. From the corollary immediately above, second-best optimal parking capacity is decreasing in the on-street parking fee. The proposition follows immediately upon noting that first-best optimal parking capacity coincides with second-best parking capacity with the first-best on-street parking fee.

\subsection{Stability}

A complete analysis of the stability of the (unique) saturated, steady-state equilibrium would be complex. The initial conditions would have to be specified in terms not only of the stock of cars in-transit, cruising for parking, and parked, but also the corresponding distribution functions in terms of length of stay in the corresponding pool. The number of entrants into the system as a function of time would depend on expectations concerning in-transit time and expected cruising-for-parking time, both as a function of entry time. 
And account would have to be taken of the possibility that the system would get stuck, due to density exceeding jam density, or that parking might be unsaturated along part of the adjustment path.

We shall touch on some of the issues by considering a simple variant of the basic model in which travel distance and visit length are Poisson distributed in the population rather than being constant. These simplifying assumptions allow the history of the system to affect the equations of motion only through the stocks of individuals in-transit, cruising for parking, and parked. We furthermore assume that demand to enter the system at time $u$ is a function only of the perceived full price of a car with mean $m$ and $l$ at time $u$, and that this perceived full trip price is $\hat{F}=\rho(m t(T(u), C(u), W, P)+C(u) l / P)+f l$ when parking is saturated, and $\hat{F}=\rho m t(T(u), 0, W, P)+f l$ when parking is unsaturated. Under these assumptions, the equations of motion when parking is saturated and cars are cruising for parking are

$$
\begin{aligned}
\dot{T}(u) & =D\left(\rho\left(m t(T(u), C(u), W, P)+\frac{C(u) l}{P}\right)+f l\right)-\frac{T(u)}{m t(T(u), C(u), W, P)} \\
\dot{C}(u) & =\frac{T(u)}{m t(T(u), C(u), W, P)}-\frac{P}{l}
\end{aligned}
$$

where $m$ and $l$ are now the means of the Poisson distributions. When parking is unsaturated, there are no cars cruising for parking and the equations of motion depend on the stock of occupied parking spaces, $S(u)$ :

$$
\begin{aligned}
& \dot{T}(u)=D\left(\rho(m t(T(u), 0, W, P)+f l)-\frac{T(u)}{m t(T(u), 0, W, P)}\right. \\
& \dot{S}(u)=\frac{T(u)}{m t(T(u), 0, W, P)}-\frac{S(u)}{l} .
\end{aligned}
$$

Account also needs to be taken of the possibility of transition between saturated and unsaturated parking.

We have proved ${ }^{14}$ that, with the equations of motion (22) and (23), a saturated parking equilibrium with $C>0$ is locally stable. Our investigation of global stability uncovered two distinct reasons why the saturated parking equilibrium may not be globally stable ${ }^{15}$. The first, which is intuitive, is that if there is a jam density and if the system starts off in a situation where the stock of cars in transit exceeds the jam density, the system remains jammed. The second is that, depending on initial conditions, the system may move towards

\footnotetext{
${ }^{14}$ The proofs are available from the authors on request.

${ }^{15}$ One might argue the possibility of a limit cycle but under our specifications a limit cycle is ruled out by Bendixson's (1901) Nonexistence Criterion.
} 
$\mathrm{A}$

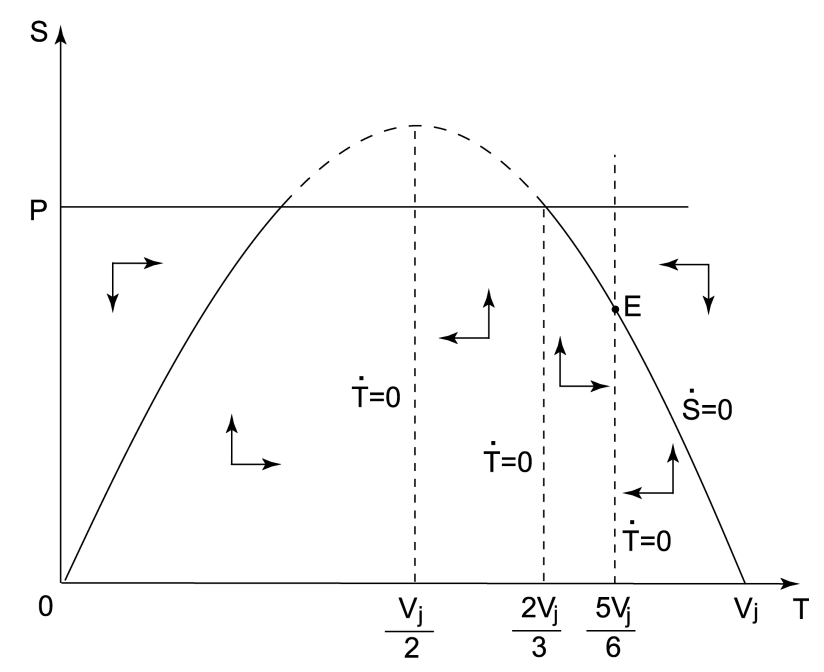

$\mathrm{B}$

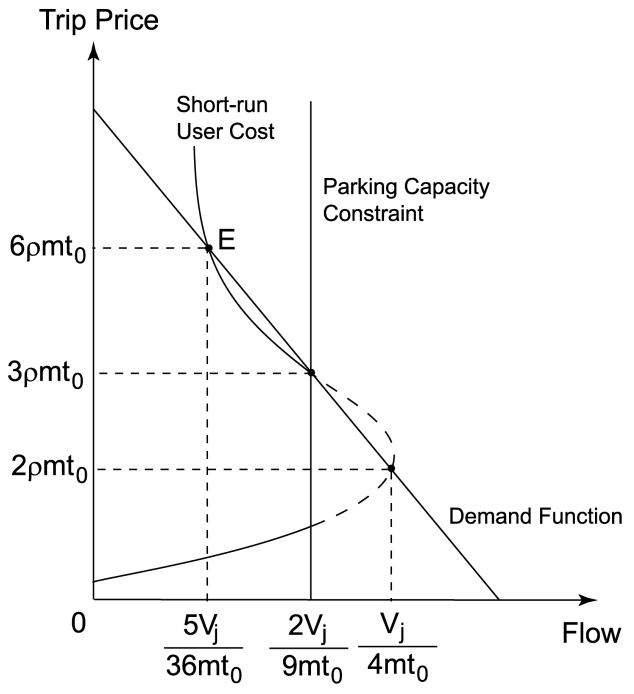

Notes:

1. Congestion function is given by $t=\frac{t_{0}}{1-\frac{V}{V_{j}}}$, where $V=C+T$ is density and $V_{j}$ jam density.

2. Demand function is given by $f=a-b \rho m t$ with $a=\frac{11 V_{j}}{36 m t_{0}}$ and $b=\frac{V_{j}}{36 \rho\left(m t_{0}\right)^{2}}$.

3. The dashes along $\dot{S}=0$ for $S>P$ in panel A and for the short-run user-cost in panel B indicate that in this region parking is saturated so that (24) and (25) do not apply.

Figure 6: A situation with both a locally stable saturated equilibrium and a locally stable unsaturated equilibrium with hypercongested traffic

a locally stable, unsaturated parking equilibrium with hypercongested traffic ${ }^{16}$, at a solution $\dot{T}=0$ and $\dot{S}=0$ for (24) and (25). This situation, portrayed as point $E$ in Figure 6, is the same as the familiar, diagrammatic depiction of a hypercongested equilibrium, due to Walters (1961), with the addition of the parking capacity constraint.

\section{$5 \quad$ Numerical Policy Analysis}

We start off by parameterizing/calibrating a numerical example. We then employ the example to perform a couple of policy exercises. The model admits only two policy instruments, the on-street parking fee and parking capacity.

\footnotetext{
${ }^{16}$ There is an unresolved debate in the literature concerning whether stable, hypercongested equilibria can occur in practice (see Verhoef (2001)). The stable, hypercongested equilibrium in our model appears logically sound, and the assumed adjustment mechanism seems sensible.
} 


\subsection{Parameterization/calibration}

Recall that the steady-state, saturated parking equilibrium is characterized by (3) and (4). This pair of equations involves a demand function, a congestion function, and several parameters. The following parameters are assumed:

$$
m=2.0, \quad l=2.0, \quad f=1.0, \quad \rho=20.0, \quad P=3712 .
$$

Units are in miles and hours. The in-transit travel distance is 2 miles; the visit length is 2 hours; the on-street parking fee is $\$ 1.00$ per hour; the value of time is $\$ 20.00$ per hour; and the number of on-street parking spaces corresponds (according to calculations made below) to parking on one side of every street but not the other. The on-street parking fee is that charged in downtown Boston; the value of time is somewhat on the high side, but is chosen taking into account that driving on city streets is less pleasant than on freeways and that downtown drivers are typically well off and busy. $P$ is calculated using the following assumptions concerning parameters. The block spacing, $b+W$, is 0.125 miles; road width, $W$, is 0.00625 miles (33 feet); and a parking space is 0.0040 miles (21.12 feet) long and 0.002083 (11 feet) wide. With allowance made for crosswalks ( 7.26 feet or 0.001375 miles) at each end of a block, 29 cars can be parked on one side of a block. Assuming parking on one side of the street, and hence on two sides of each block, implies 58 cars parked around each block and, with 64 blocks per square mile, 3712 parking spaces per square mile.

We shall employ a simple specification of the congestion technology. The general form is $t=t(T, C, W, P)$. We particularize as follows. Assume, first, that the function is weakly separable between $(T, C)$ and $(W, P)$; refer to the sub-function $V(T, C)$ as the effective density or volume function, and $\omega(W, P)$ as that effective capacity function. Second, assume the travel time depends on the volume-capacity ratio, as is standard, so that $t=t(V(T, C) / \omega(W, P))$. Let the volume function be $V=T+1.5 C$, so that a car cruising for parking contributes 1.5 times as much to congestion as a car in transit. Last, assume that Greenshield's relation (1935) holds, so that the velocity of cars is a negative, linear function of traffic volume, with free-flow velocity $\bar{v}\left(=1 / t_{0}\right)$ and jam density or volume $V_{j}$. With these assumptions,

$$
t=\frac{t_{0}}{1-\frac{V}{V_{j}}} .
$$

Finally, we assume that jam volume equals a constant, $\Omega$, times the fraction of the road not designated for parking, implying that

$$
V_{j}=\Omega\left(1-\frac{P}{11136}\right)
$$


This form of the congestion function is consistent with intersection congestion theory (Arnott (1990)). We assume $t_{0}$, free-flow travel time, to be .05 hours per mile, which corresponds to a free-flow travel speed of 20 m.p.h. A standard estimate for the elasticity of demand for peak-period traffic is 0.2 , and the constant is chosen so that the mean full price of a trip in the base situation described is $\$ 15$. Thus,

$$
D(F)=D_{0} F^{-0.2}
$$

with $D_{0}=3190.04$. Making the additional assumption that in the base case equilibrium 30 percent of cars on the road are cruising for parking allows us to calibrate $\Omega=2667.2$.

\subsection{Policy exercises}

We shall perform a number of policy exercises. The parameters for each exercise are recorded in Table 2, and the results are recorded in Table 3.

\begin{tabular}{lcccc}
\hline \hline & $\begin{array}{c}f=1, \quad P=3712 \\
\text { (Base Case) }\end{array}$ & $f^{*}, \quad P=3712$ & $f=0, P^{* *}$ & $f^{*}, P^{*}$ \\
\hline$m$ & 2.0 & 2.0 & 2.0 & 2.0 \\
$l$ & 2.0 & 2.0 & 2.0 & 2.0 \\
$\rho$ & 20.0 & 20.0 & 20.0 & 20.0 \\
$b$ & 0.11875 & 0.11875 & 0.11875 & 0.11875 \\
$W$ & 0.00625 & 0.00625 & 0.00625 & 0.00625 \\
$t_{0}$ & 0.05 & 0.05 & 0.05 & 0.05 \\
$D_{0}$ & 3190.04 & 3190.04 & 3190.04 & 3190.04 \\
$\Omega$ & 2667.2 & 2667.2 & 2667.2 & 2667.2 \\
$V_{j}$ & 1778.2 & 1778.2 & & \\
$f$ & 1.0 & & & \\
$P$ & 3712 & 3712 & & \\
\hline \hline
\end{tabular}

Notes:

1. * denotes first-best

2. ** denotes second-best

3. Blank cells correspond to endogenous variables

Table 2: Model Parameters: Basic Model

We start off with the base case. Recall that it was calibrated so that, with half the curbside allocated to parking and a parking meter rate of $\$ 1.00 / \mathrm{hr}$., 30 percent of the cars on the road are cruising for parking in the saturated steady-state equilibrium. The situation is therefore one of heavy but not extraordinarily heavy congestion. Travel speed is 4.4 m.p.h., 


\begin{tabular}{lcccc}
\hline \hline & $\begin{array}{c}f=1, P=3712 \\
\text { (Base Case) }\end{array}$ & $f^{*}, \quad P=3712$ & $f=0, P^{* *}$ & $f^{*}, P^{*}$ \\
\hline$T$ & 844.5 & 210.5 & 349.5 & 302.7 \\
$C$ & 361.9 & 0.0 & 0.0 & 0.0 \\
$V$ & 1387.5 & 210.5 & 349.5 & 302.7 \\
$P$ & & & 5248 & 4839.0 \\
$t$ & 0.2275 & 0.05671 & 0.06641 & 0.06255 \\
$\frac{1}{t}$ & 4.396 & 17.63 & 15.06 & 15.99 \\
$\rho m t=\frac{\rho T l}{P}$ & 9.100 & 2.268 & 2.656 & 2.502 \\
$\frac{C l}{P}$ & 0.1950 & 0.0 & 0.0 & 0.0 \\
$\rho \frac{C l}{P}$ & 3.900 & 0.0 & 0.0 & 0.0 \\
$f$ & & 6.366 & & 0.7412 \\
$F$ & 15.00 & 15.00 & 2.656 & 3.984 \\
$R C$ & 13.00 & 2.268 & 2.656 & 2.502 \\
$\Delta S S$ & & 19919 & 22421 & 22624 \\
\hline \hline
\end{tabular}

Notes:

1. Blank cells correspond to exogenous variables.

2. All figures are computed on the assumption

that the marginal cost of public funds equals one.

Table 3: Numerical Solutions: Basic Model

and the average cruising-for-parking time is 0.2 hours (or 12 minutes). The full trip price is $\$ 15.00$, comprising $\$ 9.10$ for in-transit travel time cost, $\$ 3.90$ for cruising-for-parking time cost, and $\$ 2.00$ for parking at the destination. The user cost, which equals the resource cost per individual, $R C$, is $\$ 13.00$ per hour.

The first policy exercise we perform is to raise the parking fee to the optimal level, where cruising for parking is just eliminated (consistent with Proposition 1), holding constant the proportion of curbside allocated to parking. This level is $\$ 6.37 / \mathrm{hr}$. Recall from the earlier discussion that this does not alter the entry flow, which is determined by the steady-state condition that the entry flow equal the exit rate from parking, since $P$ is held constant and since the equilibrium remains saturated. Thus, the full trip price does not change but its composition does. Eliminating cruising for parking reduces congestion by so much that travel speed increases to 17.6 m.p.h., so that in-transit travel cost falls to $\$ 2.27$, of which $\$ 0.27$ is due to congestion. In the base case, the individual cost of congestion - the value of time lost due to congestion was $\$ 11.00, \$ 7.10$ of which is the value of time lost in transit due to congestion (the in-transit time cost less what it would be with free-flow travel) with the remainder being the value of time lost cruising for parking. Raising the parking fee therefore eliminates $97.5 \%$ of the congestion cost. Since the full price remains unchanged, 
the per capita revenue raised from the toll exactly equals the reduction in the congestion cost. As noted earlier, the parking fee revenue is therefore raised with no burden at all. This policy generates a gain in social surplus $(\Delta S S)$ of $\$ 19919$ per sq.ml.-hr. If parking remains saturated for twelve hours a day, from say 7:30 a.m. to 7:30 p.m., on each of 200 business days a year, this translates into a gain of $\$ 47.8$ million dollars per sq.ml.-yr.

We now consider the second-best amount of curbside to allocate to parking when parking is provided free, taking into account that increasing parking capacity decreases jam density. This is obtained as the solution to (3) and (4) with $f$ and $C$ set equal to zero. The optimal amount of on-street parking is 5248 spaces per square mile, which corresponds to allocating 70.7 percent of curbside to on-street parking. With this increase in parking capacity, congestion almost disappears, cruising for parking is eliminated but parking remains saturated (consistent with Proposition 3), and in-transit travel costs fall to $\$ 2.66$. Thus, in this example, though not in general, most of the deadweight loss caused by underpricing curbside parking is eliminated by a significant increase in the amount of on-street parking provided. Since demand is not completely inelastic, the corresponding reduction in the full trip price from $\$ 15.00$ to $\$ 2.66$ causes the throughput to rise from 1856 cars per sq.ml.-hr. to 2624. The gain in social surplus relative to the base case may be calculated as the gain in consumer surplus plus the increase in toll revenue raised. The gain in consumer surplus per sq.ml.-hr. is $\$ 26133$ and the loss is revenue is $\$ 3712$, for a total gain of $\$ 22421$.

Our third policy exercise is to solve for the social optimum and the parking fee which decentralizes it. The amount of curbside allocated to parking is increased from 50 percent in the base case to 65.2 percent at the first-best optimum, and the meter rate is reduced from $\$ 1.00 / \mathrm{hr}$. to $\$ 0.74 / \mathrm{hr}$. As a result of these changes, cruising for parking is eliminated with parking remaining saturated (consistent with Proposition 2) and travel speed increases from 4.4 m.p.h. to 16.0 m.p.h. The efficiency gains in moving from the base case to the full social optimum are $\$ 22624$ sq.ml.-yr. Let us compare the first-best and second-best optimum with free parking. Consistent with Proposition 4, when the parking fee is set below its first-best optimal level, as is the case in this comparison, the second-best amount of on-street parking exceeds the first-best level. Also, the social surplus is of course larger in the first- than the second-best allocation, though in the example not by much.

\section{Extensions}

The basic model presented in the previous sections was useful in developing a conceptual framework for the integrated analysis of on-street parking and traffic congestion under 
saturated parking conditions, an essential element of which is cruising for parking. It is too simple however to be used as a basis for practical downtown parking policy. Most importantly, it omits two essential elements - off-street parking and alternative modes of transportation. Ch.2 in Alleviating Urban Traffic Congestion (Arnott, Rave, and Schoeb, forthcoming) extends this paper's model to treat these two essential elements. In this section, we consider the effects of modifying some of the model's other elements.

Dynamics: In Section 4.7 on the stability of steady-state equilibrium, we considered dynamics with a stationary demand function. The simplest way to extend that analysis to a non-stationary demand function is to assume, as is done in the bottleneck model (Vickrey (1969)), that there are schedule delay costs as well as travel time costs, and that travel time over the rush hour evolves so that the equilibrium utility level is constant over the departure period.

Spatial heterogeneity: The assumption that the downtown area is spatially homogeneous considerably simplified the analysis. In fact, of course, there is considerable variation in the number of trips by block in the downtown area. With spatial homogeneity it was natural to assume that individuals look for parking on their destination block. But with spatial heterogeneity, it is natural to assume instead that individuals decide which block to search for parking on so as to minimize the sum of expected cruising-for-parking costs and walking costs. Another complication is that with spatial heterogeneity, on some trips, such as for shopping, individuals have a choice of destination. Practical application of any downtown parking model requires the simultaneous treatment of both dynamics and spatial heterogeneity. Their simultaneous treatment should introduce no new conceptual issues but will be computationally challenging.

Individual heterogeneity: Individuals can differ according to their demand functions, trip lengths, visit durations, values of time, and behavior in traffic, as well as in the cars they drive. The previous analysis can be extended straightforwardly to treat all these elements of heterogeneity. Policy variables may be conditioned on observable but not unobservable characteristics. In the basic model, there is no scope for sorting. But in more complicated models, sorting may occur on the basis of both observable and unobservable characteristics. Sorting between on- and off-street parking occurs in the sequel to this paper. Sorting would occur in an extended version of the model of this paper in which different parking fees are charged for different meters ${ }^{17}$.

Trip length and visit duration: The model allows for the possibility that individuals will vary the number of trips they take downtown according to the full trip price. Other

\footnotetext{
${ }^{17}$ Those with higher values of time and shorter parking durations would choose the parking spots with the higher meter rates since the expected cruising-for-parking time for them would be lower.
} 
behavioral margins are the trip length $m$ and visit duration $l$. We know of no empirical work investigating the responsiveness of behavior on these margins to full trip price.

Illegal parking: Rather than cruising for on-street parking, an individual may choose instead to park on street in an undesignated parking spot, to double park or to park on the sidewalk. We implicitly ruled these choices out but in some cities such behavior is commonplace. Analyzing these alternatives will require modeling parking enforcement (see Calthrop (2001b)). Double parking also arises when individuals stop and wait for a parking spot to be vacated rather than circling the block.

Entry and exit parking congestion: This paper is the first to analyze the effect of cruising for parking on traffic congestion. There is another channel through which onstreet parking contributes to traffic congestion - entry into and exit from on-street parking locations. This could be modeled by making the travel time function dependent on not only the density of cars in transit and cruising for parking but also the turnover rate of on-street $\operatorname{parking}^{18}$.

Resident parking: Most cities have on-street resident parking even in the downtown area. The model could accommodate this by assuming that there are two groups of individuals, residents and non-residents. Upon completion of a visit, a non-resident would simply exit the system - as occurs in the basic model — but a resident would return home and park on street there. The government would then have four policy instruments, the resident and non-resident parking fees, and the curbside allocated to resident and non-resident parking. A political economy module could be added to explain observed policy choices.

Through traffic: The paper ignored through traffic ${ }^{19}$. In our paper, by reducing cruising for parking a rise in the on-street parking fee was able to reduce traffic congestion considerably. The corresponding benefits could be substantially diminished if the reduction in traffic congestion induces a substantial increase in through traffic.

\section{Concluding Comments}

This paper has explored the properties of a simple model that integrates saturated, on-street parking and traffic congestion. Since cruising for parking for a longer time raises the full trip price, the stock of cars cruising for parking adjusts to clear the market for on-street parking. A central element of the model, which will play a more important role in the sequels to the paper, is that cars cruising for parking add to traffic congestion. One major result is that,

\footnotetext{
${ }^{18}$ We thank Marvin Kraus for this point.

${ }^{19}$ We thank Ken Button for this point.
} 
whether or not the amount of on-street parking is optimal, it is efficient to raise the on-street parking fee to the point where cruising for parking is eliminated without parking becoming unsaturated. The full trip price and hence consumer surplus is unchanged, and revenue is generated for the government. Another major result is that if the parking fee is fixed at a sub-optimal level, it is second-best optimal to increase the amount of curbside allocated to parking until cruising for parking is eliminated without parking becoming unsaturated ${ }^{20}$.

The model is a useful first step towards the development of an integrated model of downtown parking and traffic congestion that can be employed in practical policy analysis. But in its current form it is too simple to provide useful policy prescription. It omits two practically very important features of downtown transportation - off-street parking and alternative modes of transportation, of which mass transit is especially important. These features will be added to the model in a pair of sequel papers. We now discuss briefly why it is essential to consider these two features in deciding on downtown parking policy.

Consider first adding private off-street parking to the model of this paper, and to simplify assume that the overall demand for downtown trips is fixed. With identical individuals, the time spent cruising for on-street parking will adjust such that the full prices of onand off-street parking are equalized. That on- and off-street parking are perfect substitutes should eliminate private off-street parking operators' market power. In this environment, raising the on-street parking fee will generate a "triple dividend." Not only will time lost cruising for parking be converted into revenue, but also the reduction in traffic congestion will cause the full price for off-street parking and hence the equilibrium full price to fall. The situation is more complicated if individuals are heterogeneous. If there is cruising for on-street parking, individuals will sort themselves between on- and off-street parking on the basis of both observable and unobservable characteristics. On- and off-street parking will no longer be perfect substitutes and, since off-street parking facilities are typically located some distance from one another, off-street parking operators will have market power, which they will exercise through setting parking fee schedules that are non-linear in parking duration. In such a setting, if the on-street parking meter rate cannot be set at the efficient level, the determination of optimal parking policy, which may include time restrictions for on-street parking, becomes a complicated exercise in the theory of the second best.

Incorporating mass transit into the model would be routine were it not for the economies of scale mass transit exhibits. To exploit these scale economies, the City of Boston has a policy of restricting the amount of off-street parking. Doing so, it reasons, will raise the relative price of off-street parking, which will encourage modal switching to mass transit, lowering the full price of mass transit and hence the equilibrium full price. With identical

\footnotetext{
${ }^{20}$ This result no longer applies when there is off-street as well as on-street parking.
} 
individuals, this reasoning is sound. But with individual heterogeneity, the effects of the policy are far more complicated and its wisdom is open to question.

In the model presented in this paper, it is efficient to raise the on-street parking fee so that cruising for parking is eliminated without parking becoming unsaturated. This result appears to be very robust, continuing to apply when off-street parking, mass transit and individual heterogeneity are introduced. Why then do local governments virtually everywhere persist in setting the on-street parking fee below the efficient level ${ }^{21}$ ? This question points to the probable importance of introducing political economy into the policy analysis.

\footnotetext{
${ }^{21}$ In downtown Boston, on some streets parking is restricted to residents, on others it is provided free, and on others there are meters with a $\$ 1.00 / \mathrm{hr}$. fee. A variety of time restrictions is also employed.
} 


\section{References}

[1] Anderson, S., and A. dePalma. 2004. The economics of pricing parking. Journal of Urban Economics 55: 1-20.

[2] Arnott, R. 1990. Signalized intersection queuing theory and C.B.D. auto congestion. Economics Letters 33: 197-201.

[3] Arnott, R., A. dePalma, and R. Lindsey. 1992. A temporal and spatial equilibrium analysis of commuter parking. Journal of Public Economics 45: 301-335.

[4] Arnott, R., and J. Rowse. 1999. Modeling parking. Journal of Urban Economics 45: 97-124.

[5] Arnott, R., R. Schoeb, and T. Rave. forthcoming. Alleviating Urban Traffic Congestion. Cambridge, MA. MIT Press.

[6] Bendixson, I. 1901. Sur les corbes définies par des équations différentielles. Acta Math. 24: 1-88.

[7] Calthrop, E. 2001a. Essays in urban transport economics. PhD thesis number 151, Katholieke Universiteit Leuven.

[8] Calthrop, E. 2001b. When consumers can decide not to pay a tax: enforcing and pricing urban on-street parking space. Katholieke Universiteit Leuven Working Paper 2001-10.

[9] Calthrop, E., S. Proost, and K. Van Dender. 2000. Parking policies and road pricing. Urban Studies 37: 63-76.

[10] Douglas, R. 1975. A parking model - the effect of supply on demand. American Economist 19: $85-86$.

[11] Glazer, A., and E. Niskanen. 1992. Parking fees and congestion. Regional Science and Urban Economics 22: 123-132.

[12] Greenshield, B. 1935. A study of traffic capacity." Highway Research Board Proceedings 14: 448-477.

[13] Rouwendal, J., E. Verhoef, and P. Rietveld. 1999. Congestion caused by speed differences. Journal of Urban Economics 45: 533-566.

[14] Shoup, D. 2005. The High Cost of Free Parking. American Planning Association.

[15] Verhoef, E. 2001. An integrated dynamic model of road traffic congestion based on simple car-following theory: exploring hypercongestion. Journal of Urban Economics 49: 505-542.

[16] Vickrey, W. 1969. Congestion theory and transport investment. American Economic Review Papers and Proceedings 59: 251-260.

[17] Walters, A. 1961. The theory and measurement of private and social cost of highway congestion. Econometrica 29: 676-699.

[18] Westin, R., and D. Gillen. 1978. Parking location and transit demand. Journal of Econometrics, 8: $75-101$. 